\title{
A RELAÇÃO DA MÃE COM SUAS FIGURAS DE APOIO FEMININAS E OS SENTIMENTOS EM RELAÇÃO À MATERNIDADE
}

\author{
Rita de Cássia Sobreira Lopes \\ Laura Pithan Prochnow \\ Cesar Augusto Piccinini
}

\begin{abstract}
RESUMO. O presente estudo investigou a relação da mãe com suas figuras femininas de apoio e os sentimentos em relação à maternidade no primeiro trimestre de vida do bebê. Dele participaram 47 mães primíparas, de níveis socioeconômicos variados, que tinham uma relação estável com o esposo. Através de uma entrevista individual investigou-se quem eram as pessoas que davam apoio à mãe e qual sua participação. As mães relataram ter uma figura feminina de apoio (98\%). Na maioria dos casos (54\%) estas figuras serviram de modelo de identificação, sendo o maior percentual (47\%) delas a própria mãe. Os companheiros foram mencionados em todos os casos como alguém que oferecia ajuda nos cuidados com o bebê e/ou nas atividades domésticas. Os achados apoiam a literatura, a qual indica que, apesar da importância do companheiro, figuras femininas de apoio se destacam neste momento da maternidade, por apoiarem e acompanharem, e também por valorizarem e instruírem a nova mãe, servindo-lhe de modelo de identificação.
\end{abstract}

Palavras-chave: Figuras femininas de apoio; sentimentos maternos; modelos de identificação.

\section{MOTHER'S RELATIONSHIP WITH FEMALE SUPPORT FIGURES}

\begin{abstract}
The present study investigated the mother's relationship with her female support figures and the feelings regarding motherhood, in the first quarter of the baby's life. Forty-seven primiparus mothers, of varied socioeconomic levels, with a stable relationship with their partners, took part in the study. Through an individual interview we investigated who were the people who gave support to the mother and which was their participation. The mothers said they had a female support figure $(98 \%)$ and in most cases $(54 \%)$ these women served as identification models, being most of them $(47 \%)$ their own mothers. The partners were mentioned in all cases as somebody who offered help in caring for the baby and/or in the domestic activities. The findings support the literature that indicates that in spite of the importance of the husband, female support figures are very important during this period, to give support, be together, as well as to value and instruct the new mother, serving as identification models for them.
\end{abstract}

Key words: Female support figures; maternal feelings; identification models.

\section{LA RELACIÓN DE LA MADRE CON SUS FIGURAS FEMENINAS DEL SOPORTE Y LOS SENTIMIENTOS DE LA MADRE EN RELACIÓN CON LA MATERNIDAD}

RESUMEN. El estudio actual investigó la relación de la madre con sus figuras femeninas del soporte y los sentimientos de la madre en relación con la maternidad en el primer trimestre de la vida del bebé. Participaron del estudio 47 madres primíparas, de niveles socioeconómicos variados, que tenían una relación estable con el compañero. A través de una entrevista individual fue investigado quién eran las personas que dieron soporte a la madre e cuál fue este soporte . Las madres que diceron ter una figura femenina de soporte (98\%) y en la mayoría de los casos (54\%) estas figuras fueron el modelo de identificación, siendo la mayoría de (47 \%) la propia madre. Los compañeros fueron mencionados en todos los casos como alguien que ofreció la ayuda en las preocupaciones con el bebé yo en las actividades domesticas. Los descubrimientos respaldan la literatura que demuestra que a pesar de la importancia del compañero, figuras femeninas de soporte se destacan en este momento de la maternidad por apoyar y acompañar y también por valorar y enseñar a la nueva madre, sirviendo de modelo de identificación esta.

Palabras-clave: Figuras femeninas del soporte; sentimientos maternales; modelos de identificación.

Doutora em Psicologia. Professora do PPG-Psicologia da UFRGS e pesquisadora do CNPq, Brasil.

\# Psicóloga. Mestre em Psicologia do Desenvolvimento. Professora coordenadora do Curso de Psicologia da ULBRA de Santa Maria, RS, Brasil.

II Doutor em Psicologia. Professor do PPG-Psicologia da UFRGS e pesquisador do CNPq, Brasil. 
O nascimento de um filho é uma fase que traz riscos de crises e desequilíbrios para a vida de qualquer mãe, especialmente para as primíparas, tendo-se em vista as profundas mudanças que a acompanham. Isto se reflete tanto no papel social da mulher e na necessidade de novas adaptações quanto no reajustamento de sua identidade (Maldonado, 2000).

Nesse período, a mãe primípara tem que reorganizar muitas coisas em sua vida, pois tem que fazer tanto o luto de um corpo mudado pela gestação quanto o luto de sua própria identidade, em que ela deixa de ser somente filha, esposa e profissional e torna-se mãe. A nova mãe passa também a ter que desempenhar várias tarefas (Brazelton \& Cramer, 1992), entre elas as de aceitar o fim abrupto do sentimento de fusão com o feto e das fantasias de completude, adaptar-se a um novo ser que evoca sentimentos de estranheza, sofrer o luto pela perda do bebê imaginário e perfeito, suportar o medo de lidar com o bebê e feri-lo, além de aprender a tolerar as exigências provocadas pela total dependência da criança. Assim, o que acontece para a mulher após o parto não é, de forma alguma, o radioso paraíso com o qual a lenda anuncia a chegada do bebê (Szejer \& Stewart, 1997).

O encontro com o filho recém-nascido demanda da mulher novos ajustes e adaptações, pois o parto inaugura uma nova forma de relação entre mãe e filho (Soulé, 1987). A mãe deverá estar preparada não só para a separação anatômica, mas também para a adaptação a um bebê em particular e para um novo relacionamento, que incluirá a combinação das suas expectativas e fantasias com os comportamentos de um ser real (Brazelton \& Cramer, 1992). Essa nova mãe irá se confrontar com as características do bebê real, que podem ser bastante diferentes do que ela imaginou durante a gestação, e terá também que se deparar com o seu desempenho real como mãe, que pode se distinguir do idealizado durante a gravidez (Donelli, 2003).

A mulher, durante toda a gravidez, faz uma preparação, com expectativas, sonhos, medos e fantasias sobre como será o seu bebê, como ela desempenhará o papel de mãe e como o seu companheiro será como pai e como será sua vida com a chegada do bebê (Stern, 1997). Essa preparação, segundo Stern, é fundamental para a construção da identidade materna. As bases da construção desta identidade podem ser encontradas na infância da própria mulher (Zalcberg, 2003). A mulher, quando ainda menina, cria, a partir da interação com sua mãe, um modelo de mãe para si, no qual se espelha para brincar com suas bonecas e que futuramente poderá utilizar na interação com seus filhos.

Como foi mencionado anteriormente, tornar-se mãe é um processo de construção que demanda um trabalho de preparação que vai capacitar a mãe a cuidar de seu bebê. Desde a gestação, segundo Winnicott (1956/2000), a mulher entra num estado especial, numa condição psicológica por ele denominada "preocupação materna primária". Tal condição se caracteriza por um estado de sensibilidade aumentada, que se desenvolve gradualmente ao longo da gravidez e dura até algumas semanas após o parto. O seu objetivo é capacitar a mulher a se preocupar com seu bebê, permitindo que sejam temporariamente excluídos seus outros interesses, além de possibilitar que a mãe se coloque no lugar do bebê para que possa ser responsiva às necessidades dele. Para Winnicott (1956/2000), o estabelecimento da preocupação materna primária permite ao bebê revelar suas tendências de desenvolvimento, experimentar um movimento espontâneo e dominar as sensações apropriadas a esta fase de sua vida. Esta condição requer um trabalho psicológico da mãe, pois não é algo natural.

A constelação da maternidade, sugerida por Stern (1997), engloba o conceito de preocupação materna primária de Winnicott (1956/2000). Stern sugere que com o nascimento de um bebê, especialmente do primeiro, o status e a identidade da mulher mudam radicalmente, já que após o parto a mãe entra nessa nova e única organização psíquica. Tal constelação, tomada como organizadora psíquica, determinará novas tendências de ações, sensibilidades, fantasias, medos e desejos. A duração dessa organização é temporária, podendo se estender por meses e até por anos, mas seja qual for essa duração, ela se torna o eixo organizador dominante da vida psíquica da mulher, ficando de lado organizadores anteriores, tais como o complexo edípico. A constelação da maternidade possui uma trilogia de preocupações e discursos diferentes, inter-relacionados, que exigem da mulher - agora mãe - reelaborações mentais. Esta trilogia refere-se ao discurso da mãe com sua própria mãe, seu discurso consigo mesma e seu discurso com o bebê. Essa trilogia da maternidade passa a ser sua principal preocupação.

A constelação da maternidade também possui quatro temas centrais, os quais podem ser entendidos como as novas tarefas que a mãe tem que desempenhar. O primeiro tema é denominado por Stern (1997) de vida e crescimento, e está relacionado com as capacidades maternas de manter a vida e o crescimento do bebê, além de promover seu 
crescimento e desenvolvimento físico. O segundo tema é chamado pelo autor de "relacionar-se primário". Este envolve a capacidade da mãe de envolver-se emocionalmente com o bebê, de forma suficientemente autêntica para que promova o seu desenvolvimento psíquico. É neste segundo tema que pode ser visualizada a "preocupação materna primária" de Winnicott. O terceiro tema refere-se à matriz de apoio. Este tema diz respeito à necessidade da mãe de criar, permitir, aceitar e regular uma rede de apoio protetora para si, para poder realizar as tarefas dos temas anteriores: manter o bebê vivo e promover seu desenvolvimento psicoafetivo. Já o quarto tema é chamado por Stern de "reorganização da identidade". A mãe precisa transformar e reorganizar sua identidade, mudando seu centro de filha para mãe, de esposa para progenitora, de profissional para mãe de família, de uma geração para a precedente. Essa reorganização é necessária para que a mulher consiga alterar seus investimentos emocionais, sua distribuição de tempo e energia e suas atividades. Neste ponto, a necessidade de modelos de identificação para a mãe é evidente, pois o trabalho mental exigido para tal transformação fará com que a mulher reviva sua história de identificações com a própria mãe e com outras figuras maternas.

Assim como a preocupação materna primária, a constelação da maternidade não é desenvolvida por todas as mulheres (Stern, 1997). Além disso, ela não é natural nem inata, mas criada a partir do contexto da maternidade em sociedades ocidentais e pósindustriais, embora possa ser influenciada por fatores psicobiológicos, especialmente hormonais. Por outro lado, mesmo sob as mesmas condições socioculturais, não são todas as mães que desenvolvem a constelação da maternidade.

Tanto Winnicott (1956/2000) como Stern (1997) descreveram dois construtos específicos, e parecem concordar em que, com o nascimento do bebê, muitas mães entram em um estado psicológico especial. Este estado pode ser facilitado e estimulado por figuras femininas que lhe ofereçam apoio, acompanhem a nova mãe, valorizem-na e lhe ofereçam informações, e, principalmente, sirvam de modelo de identificação para a mãe desenvolver seus sentimentos e suas capacidades maternas. Essas figuras devem ser mulheres mais experientes, nas quais as novas mães possam espelhar-se (Maldonado, 2000; Klaus, Kennell \& Klaus, 1993; Stern, 1997).

Alguns estudos têm sido realizados para investigar o papel de uma figura feminina no acompanhamento de mulheres no momento do parto e puerpério. Entre estes estudos destaca-se o de Klaus,
Kennell e Klaus (1993), realizado em um hospitalmaternidade da Guatemala, o qual previa que uma mulher não treinada permanecesse junto às mães durante o trabalho de parto e o nascimento do bebê. As mulheres acompanhadas nesse estudo piloto tiveram uma diminuição significativa na duração do trabalho de parto, mesmo as primíparas, além de apresentarem ausência de complicações pós-parto. A acompanhante era uma pessoa não treinada para essa função, mas era carinhosa e frequentemente tocava as mães.

Outro estudo foi realizado por esses autores (Klaus, Kennnell \& Klaus, 1993) nos Estados Unidos, e nele as parturientes foram acompanhadas por uma mulher previamente treinada, chamada de acompanhante qualificada, ou doula, palavra de origem grega que significa mulher que cuida de outra mulher. O termo é usado para identificar uma mulher que provê apoio físico, emocional e informacional contínuo para outra mulher antes, durante e após o nascimento do bebê. Os resultados indicaram que a presença de uma doula antes e durante o parto reduziu o número de cesarianas e o uso de medicamentos como a ocitocina. O número médio de horas decorrido desde a admissão hospitalar até o parto também foi significativamente menor nesse grupo, se comparado com o grupo que não teve o acompanhamento da doula. Houve uma incidência significativamente menor de problemas de parto e nascimento no grupo das mães que receberam o acompanhamento da doula. Além disso, o apoio da doula proporcionou bem-estar à mãe e ao bebê. Esses estudos também podem ser transpostos para o puerpério, no qual a doula oferece apoio para a mãe, ajudando-a a sentir-se mais segura e confiante nos cuidados com o bebê.

Assim como Stern (1997), Klaus et al. (1993) e Maldonado et al. (1996) também consideram que essa figura de apoio materna deve ser uma mulher experiente, pois deve servir de modelo de identificação para a nova mãe e transmitir conhecimentos práticos sobre como cuidar do bebê e, principalmente, favorecer a aprendizagem dos pais, deixando-os mais seguros e confiantes.

Juntos, estes estudos enfatizam a figura de apoio feminina como modelo de identificação para a nova mãe. Esta figura seria alguém em quem a mãe possa se espelhar para ajudá-la a expressar e desenvolver as capacidades e sentimentos maternos. Isso pode ser justificado porque a mãe encontra-se num estado regressivo e pode sentir-se tão desamparada quanto o bebê após o seu nascimento, principalmente se for o primeiro filho. Neste sentido, o objetivo do presente estudo foi investigar a relação de mães primíparas 
adultas com suas figuras femininas de apoio no terceiro mês de vida do bebê. Em particular se buscou investigar as figuras femininas que serviram de modelo de identificação para a mãe primípara. É na relação com essas figuras que as mães poderiam se espelhar, e essas figuras iriam ajudá-las na construção de sua identidade materna.

\section{MÉTODO}

\section{Participantes}

Participaram deste estudo 47 mães primíparas, com idades entre 20 e 37 anos $(\mathrm{M}=28,06$ anos; $\mathrm{dp}=5,28)$. Todas tinham um filho $(51 \%)$ ou filha (49 $\%$ ), com três meses de idade e viviam com o pai do bebê em situação matrimonial, como casados ou companheiros. As famílias participantes eram de níveis sócio-econômicos variados e residiam na região metropolitana de Porto Alegre.

A amostra foi selecionada, com base nos critérios descritos acima, dentre os participantes do "Estudo Longitudinal de Porto Alegre: Da Gestação à Escola” (Piccinini, Lopes, Sperb \& Tudge 1998). Este estudo iniciou acompanhando 81 gestantes, que não apresentavam intercorrências clínicas, seja com elas mesmas seja com o bebê, que era seu primeiro filho. Os companheiros também foram convidados a participar do estudo, desde que residissem juntos em situação matrimonial. Os participantes representavam várias configurações familiares (nucleares, monoparentais ou recasados), de diferentes idades (adultos e adolescentes) e com graus de escolaridade e níveis socioeconômicos variados. O estudo envolveu várias fases de coleta de dados, desde a gestação até os oito anos das crianças (gestação, $3^{\circ}, 8^{\mathrm{o}}, 12^{\mathrm{O}}, 18^{\mathrm{O}}$, $24^{\mathrm{o}}, 36^{\mathrm{o}}$ meses e $6^{\mathrm{o}}, 7^{\mathrm{o}}$ e $8^{\mathrm{o}}$ ano de vida da criança), com o objetivo de investigar os aspectos subjetivos e comportamentais das interações iniciais pai-mãe-bebê, assim como o impacto de fatores iniciais do desenvolvimento nas interações familiares, no comportamento social de crianças pré-escolares e na transição para a escola de Ensino Fundamental. O convite inicial para participar do estudo ocorreu quando a gestante fazia pré-natal em hospitais da rede pública da cidade de Porto Alegre (51,2\%), nas unidades sanitárias de saúde do mesmo município $(7,3 \%)$, por meio de anúncio em veículos de comunicação $(26,8 \%)$ e por indicação $(14,6 \%)$.

Os níveis de escolaridade das mães selecionadas para o presente estudo variaram entre primeiro grau incompleto $(8,5 \%)$ e completo $(4,2 \%)$, segundo grau incompleto $(4,2 \%)$ e completo $(23,4 \%)$, superior incompleto $(23,4 \%)$ e completo $(32 \%)$, e pósgraduação $(4,2 \%)$. O status ocupacional da profissão da mãe variou entre profissões de "baixo status" (27,6\% das mães estavam em profissões classificadas de 1 a 4 na escala de ocupações proposta por Hollingshead, 1975), de "status médio" (32\% em profissões classificadas de 5 a 6) e de "alto status" (29,8\% em profissões classificadas de 7 a 9), sendo que $10,6 \%$ das mulheres não trabalhavam. Seus companheiros tinham, em média, 31,2 anos $(\mathrm{dp}=6,6)$. Quanto à escolaridade eles variavam entre os que não haviam completado o primeiro grau $(15 \%)$, os que possuíam primeiro grau $(8,5 \%)$, segundo grau incompleto $(4,3 \%)$, segundo grau completo $(21,3 \%)$, terceiro grau incompleto $(23,4 \%)$, terceiro grau completo $(19 \%)$ e pós-graduação $(8,5 \%)$. O status ocupacional da profissão do pai variou de profissões de "baixo status" (21,3\%), isto é, classificadas de 1 a 4 na escala de ocupações proposta por Hollingshead, (1975); "status médio" (47\%), classificadas de 5 a 6; e de "alto status" (27,5\%), classificadas de 7 a 9, sendo que $4,2 \%$ dos homens não trabalhavam.

\section{Procedimento e instrumentos}

O presente estudo considerou apenas dados obtidos em duas fases de coleta de dados do estudo longitudinal descrito acima: a da gestação e a do terceiro mês de vida do bebê. Este estudo foi aprovado pelo Comitê de Ética da UFRGS (Resolução n. ${ }^{\circ}$ 20065/96). As gestantes preencheram inicialmente uma Ficha de contato inicial (GIDEP, 1998a), que investigava alguns dados demográficos sobre o casal. Com base nesta ficha foi feito um contato telefônico e o convite àquelas mães que preenchiam os critérios do estudo longitudinal. Era feita então a primeira coleta de dados na residência do casal, com a assinatura do Consentimento livre e esclarecido e a realização da Entrevista de dados demográficos (GIDEP, 1998b), com vistas a obter informações sociodemográficas adicionais da família. Era então acertada uma nova visita à família quando o bebê estivesse com três meses de idade. Nesta nova visita à residência das famílias se fazia a Entrevista sobre a experiência da maternidade e o desenvolvimento do bebê (GIDEP, 1998c), realizada individualmente com a mãe para investigar diversos temas a respeito da maternidade e do bebê. Em relação ao presente estudo, os temas particularmente considerados foram os seguintes: como estava sendo a experiência de ser mãe pela primeira vez: se foi como ela imaginava e o que saiu diferente; quais as dificuldades enfrentadas; se ela teve alguma figura feminina que lhe ofereceu apoio, quem era essa figura e como ela percebeu este apoio; se ela 
seguiu algum modelo de mãe; se houve alguém que a tivesse atrapalhado; se não considerou suficiente a ajuda.

As entrevistadoras foram treinadas para inquirir a participante quando necessário, visando ao esclarecimento de suas respostas. Em relação a todos os itens era perguntado à mãe se as situações vivenciadas estavam ocorrendo como ela havia imaginado durante a gestação, se não, o que estava sendo diferente.. A entrevista era gravada e, posteriormente, transcrita e analisada. Outros instrumentos de pesquisa também foram utilizados nessa visita, conforme descrito em Piccinini et al. (1998), mas não foram considerados no presente estudo.

\section{RESULTADOS}

Foi utilizada análise de conteúdo qualitativa (Laville \& Dione, 1999; Bardin, 1977), a fim de investigar os relatos a respeito da relação das mães com suas figuras femininas de apoio, em particular com aquelas que serviam de modelo de identificação. As categorias de análise foram definidas a partir do modelo misto, considerando a literatura (Klaus, Kennell \& Klaus, 1993; Stern, 1997) e o conteúdo das próprias entrevistas. Para fins de análise, foram consideradas cinco categorias: Figura feminina como modelo de identificação; Figura feminina de apoio que ajuda a cuidar do bebê; Figura feminina de apoio que libera a mãe para cuidar do bebê; Figura feminina que acompanha, mas não serve de apoio; Não pôde contar com uma figura de apoio feminina. Dentro de cada uma destas categorias foram também utilizadas algumas subcategorias para destacar aspectos dos relatos, conforme destaque a seguir. Além de se examinar a relação da mãe com as figuras femininas de apoio, durante a análise investigou-se também se a mãe recebera oferta de apoio e que tipo de apoio fora oferecido.

Com base nesta análise constatou-se que, em sua maioria (98\%), as mães relataram ter tido alguma figura feminina que as acompanhou durante os três primeiros meses de vida do bebê, que era a própria mãe $(78 \%)$, outra mulher $(15 \%)$ ou a mãe e outra mulher $(33 \%)$. Entre estas se destacaram algumas que serviram de modelo de identificação (54\%). Outras foram citadas apenas como cuidadoras (19\%), ou como pessoas que liberavam a mãe de atividades para que esta cuidasse do bebê $(13 \%)$. Ainda, outras mães referiram ter tido figuras femininas que as acompanharam, mas não serviram de apoio (13\%). Por fim, algumas mães expressaram que as figuras femininas atrapalharam ou não ajudaram o suficiente $(8 \%)$ e $2 \%$ referiram não ter tido nenhuma figura feminina de apoio.

Apresenta-se, a seguir, a caracterização das categorias e subcategorias, exemplificadas com verbalizações das próprias mães.

\section{Figura feminina como modelo de identificação}

Esta categoria refere-se à relação da mãe com as suas figuras femininas de apoio, as quais serviram também de modelo de identificação. Para fins de análise, várias subcategorias mereceram destaque, como: maneira de cuidar do bebê, maternagem oferecida pela figura feminina para as mães e seus bebês, a experiência da figura feminina com bebês, desenvolvimento das habilidades maternas, troca de informações, a segurança e a tranquilidade transmitidas.

Para a maioria das mães (54\%), a figura feminina de apoio serviu de modelo de identificação: " $E u$ procuro cuidar do meu filho do mesmo modo como a minha mãe cuidou de mim, acho que foi muito boa a minha educação",

\begin{abstract}
Sabe, eu acho que puxei muito pelo jeito da minha mãe de cuidar. Dizem que eu sou mandona, mas eu acho que sou exigente com os cuidados com o meu filho, assim como a minha mãe era nos cuidados comigo e com os meus irmãos.
\end{abstract}

As mães também ressaltaram a importância da maternagem oferecida pelas figuras femininas de apoio: “

A mãe ficou três meses comigo, vinte dias
antes do meu filho nascer e depois quando
ele nasceu, no primeiro mês, ela cuidou
totalmente de mim. A minha mãe até hoje
esteve aqui, ela percebeu que eu não estava
muito bem e ficou cuidando de mim;

A minha mãe vinha pra cá todo dia pra cuidar da gente.

$\mathrm{Na}$ menção a essas figuras foi ressaltada a experiência que a figura feminina tinha da maternidade "A minha mãe vinha e me ajudava, porque ela já tinha a experiência de cuidar de três filhas"; "Quando eu não sei o que ele quer, chorando,

\footnotetext{
1 Os relatos são de diferentes mães, pois relatos de uma mesma mãe não foram usados para caracterizar uma mesma categoria.
} 
aí na maioria das vezes quem descobre é a minha mãe"

Eu pergunto muito pras minhas irmãs que já têm filhos, e mesmo quando eu não pergunto, elas também dão palpite. Principalmente a que tem três filhos. Ela dá bastante palpite, coisa e tal, e eu ouço bastante. Às vezes, lógico, às vezes, eu deixo valer a minha opinião.

A experiência da maternidade das figuras femininas de apoio parece ter auxiliado no desenvolvimento das habilidades maternas em relação aos cuidados com o bebê:

Quando ele tava chorando, sabe, aquele choro que a gente dá mamá e não é isso, a gente troca a fralda e não é isso, a gente pega no colo e não é isso. Então, a mãe pegava ele, ela já tinha experiência. Então aí conseguia deixar ele quietinho. Depois de algum tempo, quando ele fazia isso eu já tinha aprendido, aí eu já sabia como fazer, porque tinha aprendido com ela.

Além disso, parece ter sido alguém que orientava a nova mãe: "A mãe foi muito sempre de orientar, se ele chorava ela dizia como tinha que fazer para acalmar. A mãe pegava ele e acomodava tranquilo";

A mãe me ajudou em tudo nos primeiros dias. Ela me mostrava como dar banho, mas eu ajudava ela, e eu era muito mole pra dá banho nele, agora já tá tudo tranquilo, agora eu cuido dele como me dá na telha, que agora já tô... já tenho autoconfiança pra cuidar.

A figura feminina também foi vista como alguém que servia para trocar informações sobre a maternidade: "A gente troca ideias sobre como é ser mãe”. Além disso, foi mencionado que o nascimento do bebê reaproximou mãe e filha:

Eu fiquei muito feliz que eu acho que ela trouxe uma coisa que eu tava precisando, a minha mãe de volta. Eu e a minha mãe nunca nos acertamos muito bem. Eu até achei que ela nem ia conhecer a minha filhinha, mas foi bem ao contrário. Ela está sempre atenciosa com a gente.

A segurança transmitida pela presença da figura feminina também foi um aspecto referido pelas mulheres:
A minha mãe ficou aqui em casa. Enquanto a minha mãe tava ali comigo tava uma maravilha, daí eu não sentia aquele medo. A presença da mãe foi fundamental depois que ela nasceu, eu me sentia segura porque qualquer coisa ela ia e me falava;

"É uma pessoa que eu confio assim... e que eu posso contar com a minha mãe. Minha mãe me dá muita força". Isto tranquilizava a nova mãe: "Ele tava chorando e eu já tava no meu limite, daí ela veio aqui e conversou comigo, me tranquilizou";

Ai, no começo foi um sufoco! Mas eu fiquei mais aliviada porque tava com a mãe. No começo, assim, quando ela era nenezinha, ela dormiu uns dias com a mãe. Porque ela chorava muito e eu não tinha jeito ainda. Depois começou indo, indo, aí eu me acostumei.

Sendo assim, a figura feminina foi considerada como a melhor pessoa para ficar com o bebê caso a mãe tivesse que sair:

Eu gostaria de deixar meu filho com a minha mãe, eu acho que seria a melhor pessoa pra cuidar dele. Porque já vai pegando o jeito da pessoa que tá com ele, então eu quero que ela pegue o nosso jeito.

\section{Figura feminina de apoio que ajuda a cuidar do bebê}

Esta categoria refere-se à relação da mãe com as suas figuras femininas de apoio que a ajudaram a cuidar do bebê. Para fins de análise, as subcategorias que mereceram destaque foram: divisão das tarefas; atenção oferecida ao bebê pela figura feminina; e alguém confiável para deixar o bebê, quando necessário.

Algumas mulheres (19\%) referiram ter tido uma figura feminina de apoio que ajudou nos cuidados com o bebê. Estas mencionaram a presença da figura feminina como uma possibilidade de dividir tarefas: "A minha sogra vai lá e troca ela"; "A minha mãe vai lá e pode dar banho nela, é uma coisa a menos pra mim”; "A minha mãe e minhas irmãs me ajudam a trocar e dar mamá”. A ajuda oferecida pelas figuras femininas de apoio foi entendida por algumas mães como uma forma de atenção aos seus bebês: "Eu gosto que a minha mãe e a minha sogra cuidem dela, porque daí ela tem mais atenção”.

A figura feminina foi apontada como a melhor pessoa para deixar o bebê quando as mães precisavam sair de casa: "Se eu tenho que sair, ir no mercado ou no centro, a minha mãe ou a minha sogra vêm aqui ou 
levam a pequenininha pra casa delas."; ou para a mãe ir trabalhar: "Quando eu trabalho ela fica com a minha mãe ou com a minha sogra.”. Algumas mães contrataram uma pessoa para ficar com o bebê para irem trabalhar: "Eu tenho uma babá para ficar com ela enquanto eu vou trabalhar" . As mães referiram que se sentiam tranquilas para irem trabalhar quando deixavam seus bebês com suas figuras femininas de apoio: "Eu fico tranquila de ir e voltar, ir e voltar, tendo gente boa cuidando e ao mesmo tempo ver que ele tá feliz. Elas são ótimas, são boas pessoas"; "Ele fica com a babá. Eu tenho muita confiança nela, é uma coisa tranquila, sempre foi tranquilo, quando vou trabalhar".

\section{Figura feminina de apoio que libera a mãe para cuidar do bebê}

Esta categoria refere-se à relação da mãe com as suas figuras femininas de apoio que a liberavam das atividades domésticas para que ela pudesse se dedicar aos cuidados com o bebê. Algumas mulheres (13\%) mencionaram ter tido uma figura de apoio feminina que as liberava dos afazeres domésticos para cuidar do bebê: "Eu tenho uma pessoa que me ajuda. De manhã ela vem, limpa a casa, faz o almoço, lava a roupa, então, o meu dever aqui dentro de casa é só o G. [filho]".

A minha cunhada tá me ajudando. Não, cuidar é eu que cuido, né, mas fazer as coisas, tudo a minha cunhada faz, né? Ela lava roupa pra mim, cozinha, arruma alguma coisa da casa. Ela diz assim: "o teu compromisso é cuidar do nenê, o resto deixa que eu faço;

"No primeiro mês, realmente, eu não mexia uma palha dentro de casa, só dedicava atenção a ela, dava de mama e repousava.". Este apoio parece ter possibilitado que as mães ficassem mais tempo com seus bebês: "Aí uma semana eu fiquei só cuidando dela, daí a minha irmã cuidava da casa".

\section{Figura feminina acompanha, mas não serve de apoio}

Esta categoria refere-se à relação da mãe com as suas figuras femininas que a acompanharam mas não deram apoio. Algumas mulheres (13\%) relataram ter uma figura que as acompanhava, mas esta não foi sentida como alguém que tenha proporcionado apoio. Dentre estes casos, algumas $(9 \%)$ relataram que o apoio da figura foi insuficiente e outras (4\%) consideraram inclusive que a figura atrapalhou a interação mãe-bebê. Para fins de análise, algumas subcategorias mereceram destaque, como: solidão, perturbação que a figura feminina causou à mãe na interação da dupla mãe-bebê, e insegurança,

Algumas mães mencionaram que a presença de uma figura feminina foi insuficiente: "Eu gostaria de ter alguém pra me ajudar”;

Eu tive dificuldade na administração da casa, porque eu tava sozinha. A primeira semana ficou uma irmã minha, a segunda semana ficou a minha sogra e depois foi todo mundo embora e ficou só nós três. Eu acho que tinha a ver com a gente assim, com a nossa atenção, de não saber muito o que fazer.

Outras relataram sentir-se sozinhas: "Me senti um pouco sozinha... da parte dos meus familiares. Às vezes eu pedia pra minhas irmãs virem aqui..

Dentre as mulheres que mencionaram ter uma figura que acompanhava mas não servia de apoio, foram ressaltadas as figuras que atrapalharam a nova mãe: "Os momentos em que eu mais me atrapalhei foi quando minha mãe tava presente";

Eu, para ser bem sincera, eu não gostava da ajuda, não porque era minha sogra, eu acho que podia ser a minha mãe ou qualquer outra pessoa. Eu sentia uma vontade de tudo eu fazer. Eu tinha medo dela fazer alguma coisa errada. Eu não queria que ela viesse, mas ela quis vir. Eu gostava de ficar bem à vontade, ela dizia que tinha que colocar calça, moletom, meia, não sei o quê, então isso eu não gostava. Então acho que nada eu gostei. Quando eu tiver outro filho, eu não quero passar por isso de novo.

Foi mencionado o fato de a presença de uma figura atrapalhar no conhecimento da dupla mãe-bebê: "Só, o mais chato que eu posso dizer foi porque, a gente não ficou sozinho porque ficou com a vó junto, então, fala uma coisa e outra, a gente fica um pouco irritada". A insegurança despertada pela acompanhante foi sentida como prejudicial à interação com o bebê:

Porque ela começa a chorar ela fica: será que ela quer mamar, será que é cocô, será que é cólica, será que é isso, será que é aquilo e, aí tu já não sabe o que fazer.

\section{Não pôde contar com uma figura de apoio feminina}

Raras foram as mulheres (2\%) que mencionaram não ter podido contar com nenhuma figura feminina nos três primeiros meses de vida do bebê: "É eu pra 
tudo. É eu durante o dia, é eu durante a noite. Não tenho ninguém pra recorrer. É tudo só comigo.

Mesmo não sendo parte do foco do presente estudo, não é possível desconsiderar as referências feitas ao esposo. Este foi citado por quase todas as mulheres como alguém que também ajudava nos cuidados com o bebê: “O B. também me ajudou um monte... porque ele dava banho, trocava fraldas... Ele tirou licença de um mês, então ele ficou com o bebê junto comigo e no primeiro mês só ele dava banho"; "Ah, ele tá sendo um ótimo pai, ele troca a fralda dele, dá banho, faz tudo isso, né? Sai com ele, gosta de sair com ele, acho que ele tá sendo um ótimo pai”;

Ele... dá uma companhia e tanto assim de ficar junto de dar apoio, de dá banho, de tá sempre com a gente, de tá sempre ajudando. Então eu comecei a ver assim, que pra mim é muito importante ele tá em casa, é toda uma segurança que ele tá me passando, eu me sinto tranquila. Então assim, tá sendo muito legal, anda junto comigo.

O companheiro também foi mencionado por quase todas as mulheres como uma figura de apoio que lhes oferecia companhia e as protegia para que elas pudessem cuidar do bebê:

Ele trabalha todo dia, mas quando ele chega em casa ele me ajuda bastante: ele faz comida, ele tira o lixo, ele lava as roupas, vai no mercado e também ele dá bastante atenção pra nós. Ele fica sentado olhando a gente brincar. Sabe, assim eu me sinto segura quando ele ta em casa com a gente.

Contudo, algumas mães destacaram que não podiam contar com a ajuda do companheiro: "O meu marido também não ajuda em nada, nadinha”

\section{DISCUSSÃO}

O presente artigo contribui para preencher uma lacuna encontrada na literatura no que diz respeito à relação da mãe com suas figuras femininas de apoio. Os estudos encontrados comumente não investigaram as figuras femininas que servem de modelo de identificação para a nova mãe. Os achados do presente estudo confirmam a literatura (Stern, 1999), a qual indica que as novas mães, após o nascimento do bebê, experimentam um profundo realinhamento emocional, e seus interesses voltam-se mais para si como mãe do que sobre seu papel de mulher ou esposa; mais para suas próprias mães e mulheres em geral do que para os homens; mais para o crescimento e desenvolvimento do bebê e menos para a carreira; mais para o seu companheiro como pai do que como homem e parceiro sexual, e mais para o seu bebê do que para todo o resto que a cerca (Stern, 1999).

Em decorrência das alterações tanto físicas quanto emocionais que acometem a vida da mulher após o nascimento de seu bebê, principalmente se este for seu primeiro filho, a mãe tende a ficar vulnerável e com muitas dúvidas sobre como cuidar do bebê (Stern, 1997, 1999; Winnicott, 1956/2000). Dessa forma, muitas mães podem sentir-se desamparadas, inseguras e até mesmo incapazes de lidar com seus filhos. Por esta razão, Winnicott (1988) refere que as pessoas que cuidam de um bebê são tão desamparadas em relação ao desamparo do bebê quanto o próprio bebê. Destarte, os achados do presente estudo corroboram a literatura, a qual indica que as mães, nesse período, estão fragilizadas, necessitando de uma matriz de apoio que as ajude, acompanhe e ofereça cuidados para que possam manter a vida e o crescimento do bebê, assim como promover seu desenvolvimento físico e psicossocial (Stern, 1997). Além disso, os resultados mostraram que a maioria das novas mães buscou este apoio em uma mulher mais experiente nos assuntos referentes à maternidade, para que fossem auxiliadas no desenvolvimento de suas próprias capacidades de exercer suas funções de mãe. A nova mãe precisa e quer ser "sustentada", valorizada, apreciada, ajudada, estruturada por uma mulher mais experiente que esteja sempre a seu lado, o que possivelmente a tornará mais segura e confiante para lidar com seu bebê.

Apesar de nas sociedades ocidentais estar havendo um relativo desaparecimento da família extensiva, com importantes consequências na ajuda tradicionalmente dispensada à mãe - ficando o apoio à mãe restrito por vezes ao companheiro -, os resultados deste estudo indicam que as novas mães continuam recebendo o apoio de uma figura feminina, que, na maioria dos casos, era sua própria mãe, sua sogra ou irmã mais experiente. Estas não apenas participaram dos cuidados com os bebês, mas também serviram de modelo de identificação para a nova mãe (Stern, 1997).

Mães que não puderam contar com o apoio de uma figura feminina mais experiente, que lhes servisse de modelo de mãe ou que as liberasse para se preocupar apenas com seu filho, descreveram-se como atrapalhadas para lidar com os cuidados do bebê e demais tarefas relacionadas à maternidade.

A constatação de que, em alguns casos, a figura feminina acompanhava, mas não servia de apoio, 
revela que nem sempre a presença de alguém representa o apoio esperado. Esses dados estão em conformidade com a literatura, a qual indica que a mãe necessita de uma figura que esteja junto com ela, mas não interfira na sua relação com o seu bebê, pois quando uma mãe é capaz de ser mãe com toda a naturalidade, jamais se deve interferir (Winnicott, 1988). A mãe precisa descobrir por si mesma as suas capacidades maternas, e na relação com seu filho/a precisa descobrir suas constantes aquisições desenvolvimentais e interacionais. Para isto, ela necessita de recursos ambientais que estimulem sua confiança em si própria. Cabe, então, às mães, conhecer as suas próprias necessidades e preocupar-se com elas no estágio inicial da vida do bebê, cabendo também insistir em sua busca de autorrealização. As figuras femininas eventualmente apontadas por atrapalharem as mães foram mencionadas como pessoas que interferiam na sua relação com o bebê, podendo se tornar perniciosas ao relacionamento mãebebê (Winnicott, 1988).

Por outro lado, os achados deste estudo também corroboram a literatura, ao indicarem que nos dias atuais, pelo menos nas sociedades ocidentais, a participação do companheiro passa a ser considerada importante nas tarefas relacionadas aos cuidados com o bebê, ao apoio emocional, na realização das atividades domésticas e na proteção da mulher para que esta possa tomar conta de seu filho (Brazelton \& Cramer, 1992; Dessen \& Braz, 2000; Klaus, Kennell \& Klaus, 1993; Stern, 1997; Teti \& Gelfand, 1997). Este fato é importante ser mencionado, pois parece que na atualidade os homens vêm se envolvendo com tarefas que tradicionalmente eram consideradas das mulheres. Tempos atrás o nascimento era considerado "assunto de mulheres", o mesmo acontecendo com os cuidados iniciais com a criança. Os homens eram mantidos a uma distância segura e só gradualmente tinham acesso ao bebê (Stern, 1997).

Os achados confirmam a literatura quando esta indica que, apesar da enorme importância do companheiro nessa matriz de apoio das mães primíparas, atualmente, é esclarecedor diferenciar seu papel comparado ao das mulheres, que tradicionalmente assumiam as funções da matriz de apoio. Os dados mostram que o companheiro participou da primeira função da matriz de apoio (Stern, 1997), que é proteger a mãe fisicamente, prover suas necessidades vitais e, por algum tempo, afastá-la das exigências da realidade externa para que ela possa dedicar-se às tarefas de manter a vida e crescimento do bebê e promover seu desenvolvimento psíquico. Além disso, os resultados mostram que o companheiro é importante como uma proteção e um para-choque físico e prático e para o apoio psicológico, porém para Stern (1997) ele não serviria de modelo de identificação para a nova mãe (Stern, 1997).

A mãe, após o nascimento do bebê, encontra-se em um estado regressivo, necessitando de uma figura que possa "ser mãe para a mãe" (Klaus et al., 1993). Os achados do presente estudo indicaram que as novas mães, após o nascimento do bebê, ativaram a segunda função da matriz de apoio (Stern, 1997), que consiste na maternagem para a nova mãe, ou seja, o oferecimento de um acompanhamento para que ela se sinta valorizada e apoiada após o nascimento do filho. Como mostrado no presente estudo, esta função foi desempenhada por uma mulher mais experiente que lhe serviu de modelo de identificação. Além disso, pôde-se constatar que em alguns casos ocorreu uma tendência à reativação e reorganização do relacionamento da mãe com as figuras femininas de sua vida, normalmente, sua própria mãe. Esta função fica, então, reservada, de modo geral às mulheres, especialmente entre aquelas que passaram pela experiência da maternidade. Para algumas das novas funções que tem que desempenhar, mais do que de um companheiro, a nova mãe precisa uma mãe, avó ou outra figura feminina que lhe possa servir de espelho.

Neste sentido, é possível fazer uma analogia com a proposição de Winnicott (1988) de que a mãe deve servir de espelho para seu bebê. De acordo com esse autor, no desenvolvimento emocional do bebê o precursor do espelho é o rosto materno. O bebê, quando olha para o rosto materno, normalmente vê a si mesmo, ou seja, a mãe está olhando para o bebê e aquilo com que ela se parece se acha relacionado com o que ela vê ali. Dessa forma, a nova mãe irá encontrar na figura feminina de apoio alguém em quem, ao olhar, ela sinta a imagem materna, alguém em cuja imagem ela possa se ver refletida e com a qual ela possa se identificar. Assim, essa figura feminina pode ajudar a mãe a achar o caminho para a descoberta da identidade materna, permitindo que essa mãe entre em sintonia com o seu bebê. Como menciona Stern (1997), sem a matriz de apoio, a função materna provavelmente ficará comprometida. Mesmo assim, parece que o companheiro moderno está sendo chamado a assumir o vazio criado pelas mudanças na nossa sociedade, apesar das dificuldades que tem em fazê-lo e da eventual impossibilidade de atender a tais demandas, pelas próprias características do ser homem. Assim, apesar do esforço que eventualmente alguns companheiros fazem para "substituir", pelo menos em parte, o papel da figura materna, fica-se 
ainda sem saber até que ponto ele é capaz de atender às complexas funções deste papel na vida das novas mães.

\section{REFERÊNCIAS}

Bardin, L. (1977). Análise de conteúdo. Lisboa, Edições 70.

Brazelton, T. B. \& Cramer, B. G. (1992). As primeiras relações (M.B. Cipolla, Trad.). São Paulo, Martins Fontes.

Dessen, M.A. \& Braz, M.P. (2000). Rede social de apoio durante transições familiares decorrentes do nascimento de filhos. Psicologia, Teoria e Pesquisa, 16, 221-231.

Donelli, T. M. S. (2003). A repercussão da experiência do parto no processo de construção da maternidade. Dissertação de Mestrado Não-Publicada. Curso de Pós-Graduação em Psicologia do Desenvolvimento Humano, Universidade Federal do Rio Grande do Sul, Porto Alegre, RS.

GIDEP (1998a). Ficha de contato inicial. Instituto de Psicologia UFRGS, Porto Alegre. Instrumento Não-Publicado.

GIDEP (1998b). Entrevista de Dados Demográficos. Instituto de Psicologia - UFRGS, Porto Alegre. Instrumento Não-Publicado.

GIDEP (1998c). Entrevista sobre a Experiência da Maternidade e desenvolvimento do bebê. Instituto de Psicologia - UFRGS, Porto Alegre. Instrumento Não-Publicado.

Hollignshead, A. B. (1975). Four factor index of social status. Manuscrito Não-Publicado.

Klaus, M. H., Kennell, J. H. \& Klaus, P. H. (1993). Motheing the mother, how a doula can help you have a shorter, easier, and healthier birth. Massachusetts, Perseus Books.

Laville, C. \& Dione, J. (1999). A construção do saber. Porto Alegre, Artmed.

Maldonado, M. T. (2000). Psicologia da gravidez. São Paulo, Saraiva.

Maldonado, M. T., Dickstein, J. \& Nahoum, J. C. (1996). Nós Estamos Grávidos. São Paulo, Saraiva.

Piccinini, C. Lopes, R.C. Sperb, T. \& Tudge, J. (1998). Estudo Longitudinal de Porto Alegre, Da Gestação à Escola. Projeto Não-Publicado. Projeto Longitudinal do Curso de Pós-Graduação em Psicologia do Desenvolvimento Humano, Universidade Federal do Rio Grande do Sul, Porto Alegre, R. S.

Prado, L. C. (1996). A mãe também precisa de maternagem. Em L.C. Prado, Famílias e terapeutas - Construindo caminhos (pp.97130). Porto Alegre, Artes Médicas

Soulé, M. (1987). O filho da cabeça, o filho imaginário: seu valor estruturante dentro das trocas mãe-filho. Em T. B. Brazelton (org.), A dinâmica do bebê. Porto Alegre: Artes Médicas.

Stern, D. (1997). A constelação da maternidade: O panorama da psicoterapia pais/bebê. (M.A.V. Veronese, Trad.). Porto Alegre, Artes Médicas.

Szejer, M. \& Stewart, R. (1997). Nove meses na vida de uma mulher. (M.N.B. Benetti, Trad.). São Paulo, Casa do Psicólogo.

Teti, D. M. \& Gelfand, D. M. (1997). Maternal cognitions as mediatior of child outcomes in the context of postpartum depression. In L. Murray \& P. J. Cooper. Postpartum depression and child development (pp. 136-162). New York, The Guilford Press.

Tudge, J. \& Frizzo, G. F. (2002). Classificação baseada em Hollingshead do nível socioeconômico das famílias do Estudo Longitudinal de Porto Alegre, da Gestação à Escola. Instituto de Psicologia - UFRGS, Porto Alegre. Manuscrito Não-Publicado.

Winnicott, D. W. (1988). Os bebês e suas mães (J. L. Camargo, Trad.). São Paulo, Martins Fontes.

Winnicott, D. W. (2000). A preocupação materna primária (J. Russo, Trad.). Em D. W. Winnicott, Textos selecionados, Da pediatria à psicanálise (pp.491-498). Rio de Janeiro, Francisco Alves. (Original publicado em 1956).

Zalcberg, M. (2003). A relação mãe e filha. São Paulo, Editora Elsier.

Endereço para correspondência:

Rita de Cássia Sobreira Lopes. Instituto de Psicologia, UFRGS, Rua Ramiro Barcelos 2600/111, CEP 90035-003, Porto Alegre-RS, Brasil.E-mail: sobreiralopes@ portoweb.com.br. 